\title{
NUMB inactivation confers resistance to imatinib in chronic myeloid leukemia cells
}

\author{
Eva Garcia-Alegría ${ }^{1,5}$, M. Carmen Lafita-Navarro ${ }^{1,}$ Rocío Aguado ${ }^{2,6}$, Lucia \\ Garcia-Gutierrez ${ }^{1}$, Kyle Sarnataro ${ }^{1}$, Cristina Ruiz-Herguido ${ }^{3}$, Francisco \\ Martín ${ }^{4}$, Anna Bigas ${ }^{3}$, Matilde Canelles $^{2+}$ and Javier León ${ }^{1+}$ \\ ${ }^{1}$ Instituto de Biomedicina y Biotecnología de Cantabria (IBBTEC), CSIC-Universidad de \\ Cantabria and Dpto. de Biología Molecular, Universidad de Cantabria, Santander, Spain \\ ${ }^{2}$ Instituto de Parasitología y Biomedicina, CSIC, P. T. Ciencias de la Salud, Granada, Spain. \\ ${ }^{3}$ Stem Cells and Cancer Group. IMIM, Barcelona \\ ${ }^{4}$ Genyo, P.T. Ciencias de la Salud, Granada, Spain. \\ ${ }^{5}$ Present address: Stem Cell Hematopoiesis Group, Cancer Research UK Manchester \\ Institute, University of Manchester, Manchester, United Kingdom \\ ${ }^{6}$ Present address: Present address: Instituto Maimónides de Investigación Biomédica de \\ Córdoba (IMIBIC)-Reina Sofía University Hospital, Córdoba, Spain \\ ${ }^{\dagger}$ To whom correspondence should be addressed: \\ -Matilde Canelles \\ mcanelles@ipb.csic.es \\ Tel: 34-958-181660 \\ Fax: 34-958-181632 \\ -Javier León \\ javier.leon@unican.es \\ Tel: 34-942 201952 \\ Key words: NUMB, Imatinib, chronic myeloid leukemia
}




\section{ABSTRACT}

Chronic myeloid leukaemia $(\mathrm{CML})$ progresses from a chronic to a blastic phase, where the leukemic cells are proliferative and undifferentiated. The CML is nowadays successfully treated with BCR-ABL kinase inhibitors as imatinib and its derivatives. NUMB is an evolutionary well-conserved protein initially described as a functional antagonist of NOTCH function. NUMB is an endocytic protein associated with receptor internalization, involved in multiple cellular functions. It has been reported that MSI2 protein, a NUMB inhibitor, is upregulated in CML blast crisis, whereas NUMB itself is downregulated. This suggest that NUMB plays a role in the malignant progression of CML. Here we have generated K562 cells (derived from CML in blast crisis) constitutively expressing a dominant negative form of NUMB (dnNUMB). We show that dnNUMB expression confers a high proliferative phenotype to the cells. Importantly, dnNUMB triggers a partial resistance to imatinib in these cells, antagonizing the apoptosis mediated by the drug. Interestingly, imatinib resistance is not linked to p53 status or NOTCH signaling, as K562 lack p53 and imatinib resistance is reproduced in the presence of $\mathrm{NOTCH}$ inhibitors. Taken together, our data support the hypothesis that NUMB activation could be a new therapeutic target in CML.

\section{INTRODUCTION}

Chronic myeloid leukemia $(C M L)$ is a myeloproliferative neoplasia usually diagnosed as an indolent chronic phase characterized by the accumulation of differentiated myeloid cells, followed by an accelerated phase where myeloid cell expansion increases, and finally progresses into a blast crisis phase where the expanded myeloid cells are more immature and aggressive. The molecular hallmark of all CML is expression of the BCR-ABL tyrosine kinase. This fusion oncoprotein is the result of the 9; 22 translocation giving rise to the Philadelphia chromosome [1, 2]. BCR-ABL inhibitors as imatinib and other more recently introduced inhibitors are the frontline drugs in CML therapy [2, 3].

The available data indicate that CML is a hematopoietic stem cell malignancy where BCR-ABL leads to a progressive block of differentiation and increased genetic instability [1, $4,5]$. Although constitutive expression of BCR-ABL is sufficient to recapitulate the chronic phase, the molecular basis underlying the transition from a chronic to an aggressive blast crisis phase remains poorly understood.

NUMB is an evolutionarily well-conserved protein, initially described as a NOTCH inhibitor [6, 7]. In subsequent studies, Numb was shown to be an endocytic protein associated with receptor internalization and clathrin dependent endosomal association [8- 
12]. Numb plays a critical role in cell fate determination, displaying a complex pattern of functions, controlling asymmetric cell division, cell adhesion and migration, acting on several signaling pathways, as preTCR and Hedgehog [13, 14]. Interestingly, there is also evidence of a reduction in NUMB expression in some cancers [15-18].

The RNA-binding protein MSI2 (Musashi 2) promotes NOTCH signaling by binding to the mRNA of Numb, a negative regulator of NOTCH signaling. Recent reports demonstrated that MSI2 is upregulated in blast crisis CML, and correspondingly, NUMB was downregulated. Moreover, exogenous expression of NUMB inhibited leukemogenesis [19]. Thus, the MSI2-NUMB signaling axis plays a role in the malignant progression of CML and the promotion of a more immature aggressive myeloid leukaemia [19, 20]. Additionally, this stem cell regulator, MSI2, has been recently described as a prognosis factor in acute myeloid leukemia, being involved in the maintenance and engraftment of HSC [21], but whether this function is independent of NUMB is under debate [22].

To better define the role of NUMB in CML, we engineered a human CML cell line, K562, carrying a dominant negative NUMB form (dnNUMB). This is a truncated NUMB protein containing the $\mathrm{N}$-terminal phosphotyrosine-binding region (PTB) described as an activator of $\mathrm{NOTCH}$ signaling [23, 24]. We describe here that NUMB loss of function increased K562 proliferation and confers partial resistance to imatinib, and these effects are Notch-independent.

\section{RESULTS}

We first set out to generate K562 cells with constitutive expression of dominantnegative NUMB (dnNUMB). We used as dnNUMB the region of 163 amino acids comprising the PTB domain [23] (Fig. 1A). We added a Myc tag at the N-terminus and the Myc-PTB was inserted in the SEWP lentiviral vector backbone [25] to generate the SdnNUMBWP lentiviral vector The SEWP lentiviral vector expressing enhanced green fluorescence protein (eGFP) was used as control. The major features of these vectors are depicted in Fig 1B. We transduced K562 cells with SdnNUMBWP lentiviral particles to generated the KdnNUMB cell line and dnNUMB ectopic expression in the transduced cell lines was analyzed by intracellular flow cytometry using an anti-Myc tag antibody. As a control we also transduced cells with lentivirus driving GFP expression (KGFP). With increasing volumes of viral supernatant we obtained increasing percentages of transduced cells reaching up to $85 \%$ of the cells expressing dnNUMB protein (not shown). We selected a pool of transduced cells and the expression of dnNUMB was assessed by western blot (Fig. 1C). It is expected that the expression of dnNUMB would result in over-activation of NOTCH. Thus, to test whether KdnNUMB cells expressed a functional dnNUMB protein, we determined the mRNA levels of several NOTCH target genes. For this purpose, total RNA from KdnNUMB and control KGFP 
cells was extracted and mRNA levels of HES1, E2A, CCND1, CDK2, BCLX (BCL2L1) and MYC were analyzed by RT-qPCR. The result showed increased expression of NOTCH target genes in KdnNUMB cells (Fig.1D). This indicates that dnNUMB is impairing NOTCH signaling in K562 cells through the functional inactivation of NUMB.

We next asked whether inhibition of NUMB exerted an effect on K562 cell proliferation. The results showed that expression of dnNUMB resulted in an increased proliferation rate of KdnNUMB cells, as demonstrated by cell counting (Fig. 2A) and thymidine incorporation into DNA (Fig. 2B). In an independent approach, we labeled K562 cells expressing the dominant negative NUMB as well as control cells with bromodeoxyuridine (BrdU) for $24 \mathrm{~h}$. The results showed that $\mathrm{K} 562$ cells expressing dnNUMB proliferated more than control K562 cells (Fig. 2C). To confirm the above results in lentivirally transduced cells we also transfected K562 with a plasmidic dnNUMB expression vector (pCEFL-dnNUMB). Several stable dnNUMB-transfectant clones were selected and the dnNUMB overexpression confirmed by immunoblot (Fig. 2D). The proliferation of two of them was tested by BrdU incorporation and the results showed that these clones proliferated faster than the control cells transfected with the empty vector (Fig 2E). Altogether the results show that dnNUMB elevated the proliferation rate in K562 cells. The hyperproliferation of K562 due to dnNUMB was a striking finding given that parental K562 cells already show a high proliferation capacity.

In view of the association of NUMB-Mushashi with CML progression, we assayed the effect of dnNUMB on the response to imatinib, the front-line drug used in this leukemia. In parental K562 cells imatinib at concentrations $\geq 0.5 \mu \mathrm{M}$ readily induces cell death, as previously reported $[26,27]$. In contrast, KdnNUMB cells were partially resistant to the antiproliferative effect of imatinib, as assessed by viable cell counting (Fig. 3A). Cell cycle analysis also demonstrated a higher fraction of KdnNUMB in $S$ phase as compared to control cells. This result was reproduced in the presence of imatinib and other BCR-ABL inhibitors as dasatinib and nilotinib (Fig. 3B). The KdnNUMB cells also showed a reduced imatinib-induced apoptosis, as assessed by the cleavage of poly (ADP-ribose) polymerase (PARP) after immunoblot analysis (Fig. 3C) and the fraction of sub-G1 cells as assessed by cell cytometry (Fig. 3D). We asked if this resistance to imatinib was due to the up-regulation of BCLX, a NOTCH target gene. BCLX protein expression was determined by immunoblot in cells untreated and treated with imatinib. The results show that BCLX levels were similar in KGFP and KdnNUMB cells, and that imatinib treatment reduces these levels This reduction is even higher in KdnNUMB cells (Fig. 3E). Therefore, the partial resistance to imatinib of KdnNUMB cells was not due to increased BCLX levels. As previously reported [28, 29], K562 does not express BCL2 (Fig. 3E), and therefore BCL2 cannot be involved in imatinib resistance. 
To explore the mechanism for dnNUMB-mediated resistance to imatinib we studied the BCR-ABL kinase activity in KdnNUMB cells and in vector-expressing cells. The levels of phosphorylated BCR-ABL (which undergoes auto-phosphorylation) and CRKL (a classical BCR-ABL kinase substrate) [30] were analyzed by immunoblot. Consistent with their partial resistance against imatinib, KdnNUMB cells showed a higher BCR-ABL activity (Fig. 4A). Imatinib, however, did not impair the activity of dnNUMB as assessed by the elevated expression of different Notch-target genes (Fig. 4b). We conclude that dnNUMB confers a partial resistance of $B C R-A B L$ to the growth inhibitory activity of imatinib. It has been described that imatinib induces erythroid differentiation in K562 [31] and that NOTCH enhances erythroid differentiation in human and mouse hematopoietic cells $[32,33]$. Therefore, we tested differentiation of KdnNUMB cells, and we found that mRNA expression of erythroid genes, as erythropoietin receptor (EPOR) and several globins, was elevated in KdnNUMB cells as compared with control cells (Fig. 4C). The KdnNUMB cells also showed increased differentiation when treated with imatinib (Fig. 4C). The same result was found when $\mathrm{Y}$-globin levels were determined by immunoblotting (Fig. 4D). The fraction of hemoglobinized cells as assessed by the benzidine assay was also higher in KdnNUMB cells with respect to control cells (Fig. 4E). K562 can also be differentiated into the megakaryocytic lineage by staurosporine [34] but dnNUMB showed no effect on this differentiation (not shown).

Finally, we asked whether dnNUMB effect is a consequence of its activating effect on NOTCH or due to other effects, as NUMB is not exclusively involved in NOCTH signaling but also mediates the internalization processes for many receptors. To address this question we used a $\mathrm{y}$-secretase inhibitor (DAPT) which specifically blocks NOTCH signaling. As expected, the levels of NOTCH Intracellular Domain (NICD), the product of active cleaved $\mathrm{NOTCH}$ was increased in KdnNUMB cells with respect to parental cells, as shown by immunoblot (Fig. 5A). The effect of DAPT on both cell lines was demonstrated by the decreased levels of NICD in DAPT-treated cells KGFP and KdnNUMB cells with respect to untreated cells (Fig. 5A). We next compared the effects of DAPT on cell proliferation of dnNUMB-expressing cells and the control cells. We assayed the dose-dependent effect of DAPT (Fig. 5B) and along $72 \mathrm{~h}$ of treatment (Fig. 5D). and the results showed that DAPT decreased the fast growing phenotype of KdnNUMB cells, but much less than in control cells. This result is consistent with the fact that dnNUMB activates the NOTCH pathway, as confirmed previously shown (Fig. 1D). The NOTCH inhibitor did not modify the resistance to imatinib shown by KdnNUMB cells (Fig. 5C). Moreover, DAPT did not significantly modify the expression of CDK2, HES1 and MYC mRNA (Fig. 6A) or BCLX protein (Fig. 6B) in KdnNUMB cells with respect to control cells in the presence of imatinib. Altogether, these 
data show that the hyper-proliferative effect of NUMB inhibition and resistance to imatinib in CML cells is not primarily mediated by $\mathrm{NOTCH}$.

\section{DISCUSSION}

Here we describe an increased proliferative rate in the K562 cell line carrying a dominant negative form of NUMB. It was previously reported that repression of NUMB could be essential for maintenance of blast crisis CML [20]. However, in contrast with that report, our results show that the pro-proliferative effect associated with this repression of Numb does not depend on p53, as K562 cells are deficient in p53 [35].

This stimulation in the proliferation could be explained by the up-regulation of several targets of NOTCH pathway observed in the K562 cells expressing dnNUMB, which include proteins that stimulate cell cycle (e.g., Cdk2, Myc, and E2A). However, it seems to be independent of $\mathrm{NOTCH}$-mediated signaling, as the treatment with DAPT, a y-secretase inhibitor,didn't have, did not exert a relevant effect on the proliferative behavior of KdnNUMB cells. This is consistent with reports demonstrating that Notch inhibition does not impair K562 growth [36] and with the phenotype of dnNUMB transgenic mice, which, unexpectedly, is different from that of activated Notch transgenic mice [37, 38]. Our results suggest that pathways other than NUMB-NOTCH are being inhibited in KdnNUMB. It is conceivable that NUMB acts as endocytic adaptor for internalization of receptors required for CML cells proliferation, and dnNUMB will enhance or maintain the signaling form these receptors

Imatinib is an inhibitor of BCR-ABL, nowadays the front-line drug for CML, together with other related molecules, as dasatinib or nilotinib. One of the most important caveats for the treatment of $\mathrm{CML}$ is the acquired resistance to imatinib observed in a substantial proportion of patients due to prolonged drug exposure, which makes them refractory to this treatment and causes patient relapse [39]. We describe that dnNUMB-K562 cells show partial resistance to the cells death induced by imatinib and related molecules (dasatinib or nilotinib). This resistance is consistent with the unabated activity of BCR-ABL kinase of KdnNUMB cells in the presence of imatinib as assessed by CRKL phosphorylation. In agreement with this result, it has been recently shown in primary CML cells that NOTCH signaling leads to BCR-ABL hyperactivation [40]. It has also been reported that imatinib induces erythroid differentiation in K562 cells [31] and NOTCH activity stimulates erythroid differentiation in hematopoietic cells [32, 33]. We found that dnNUMB expression not only conferred partial resistance to imatinib-induced cell death, but also enhanced imatinibinduced differentiation. 
Further work will be required to unveil the mechanism for this interaction the interaction between NUMB and BCR-ABL. In summary, our results suggest that low NUMB levels or activity contribute to proliferation of CML cells through mechanisms independent of NOTCH and p53. This finding support the hypothesis that activation or stabilization of NUMB may act as a new therapeutic target in CML.

\section{MATERIALS AND METHODS}

Cell Culture: All K56-derived cell lines were culturing in non-tissue culture plates using RPMI 1640 medium supplemented with $10 \%$ fetal calf serum and gentamycin $(60 \mu \mathrm{g} / \mathrm{ml})$ at $37^{\circ} \mathrm{C}$ under normoxia conditions. HeLa cells were grown in DMEM with $10 \%$ fetal calf serum and gentamycin $(60 \mu \mathrm{g} / \mathrm{ml})$. $\mathrm{Kbcl} 2$ and $\mathrm{KbclX}$ cell lines were previously described [28, 29]. Cells were passaged every 3 days. Cell proliferation was assayed with a Nucleocounter (Chemometec). When indicated, cells were treated with imatinib, dasatinib or nilotinib (from LC Laboratories) or DATP (Sigma-Aldrich).

Cell cycle and erythroid differentiation analysis. Cell cycle distributions were assayed by ethanol fixation overnight and propidium iodide $(\mathrm{PI})$ staining of DNA followed by fluorescence-activated cell sorting using Guava EasyCyte Flow Cytometer (Guava Technologies), following the manufacture's instructions. Viable cell counts were determined with the same cytometer using the ViaCount assay kit. The fraction of hemoglobin-producing cells was scored by the benzidine assay essentially as described [41]

Immunoblot: Nuclear and cytoplasmic extracts were obtained using lysis buffer (1\% NP40, $0.2 \%$ SDS, $50 \mathrm{mM}$ Tris-HCl pH 7.5, $100 \mathrm{mM} \mathrm{NaCl}, 1 \mathrm{mM}$ EDTA, 10\% glycerol, $10 \mathrm{mM} \mathrm{NaF}$ and protease inhibitors) for 20 minutes at $4^{\circ} \mathrm{C}$. Lysates were cleared by centrifugation after 4 pulses ON/OFF of $30 \mathrm{sc}$ in the Bioruptor. $50 \mu \mathrm{g}$ of lysates were subjected to immunoblot as described [42]. The antibodies used were anti-MYC tag (mouse monoclonal from Santa Cruz Biotech, 9E10), anti-PARP (rabbit polyclonal, from Santa Cruz Biotech, H-250), anti-cleaved NOTCH1 (NICD, Val1744) (rabbit polyclonal from Cell Signalling), anti-BCLX (rabbit monoclonal from Cell Signalling), anti-BCL2 (mouse monoclonal from BD Transduction Laboratories), anti $\gamma$-globin (rabbit polyclonal from Santa Cruz Biotech), anti anti- $\beta$-actin (goat polyclonal from Sigma, I-19) and anti-a-tubulin (mouse monoclonal from Sigma, T6074). All antibodies were from Santa Cruz Biotech and were diluted 1:1000. The blots 
were developed with secondary antibodies conjugated to IRDye680 and IRDye800 (Li-Cor Biosciences) and visualized in an Odyssey scanner.

RNA extraction and expression analysis Total RNA was isolated using Trizol or RNeasy kit (Qiagen). For reverse transcription and polymerase chain reaction (RT-PCR), first-strand cDNA was synthesized from $1 \mu \mathrm{g}$ of total RNA using SuperScriptTM II RNase reverse transcriptase (Invitrogen) and random primers. Quantitative RT-PCR was performed with a SYBR Green PCR kit (BioRad). The expression levels were normalized to the expression of human actin mRNA $r$ human ribosomal protein S14 (RPS14). The primers used in the PCR reactions are described in Table 1.

${ }^{3} \mathrm{H}$-Thymidine incorporation: $5 \times 10^{4}$ cells per well were cultured during $72 \mathrm{~h}$ in a 96 well plate. Cultures were pulsed with $0.3 \mathrm{uCi}$ of $3 \mathrm{H}$-thymidine $(3 \mathrm{H}-\mathrm{TdR})$ for the final 15 hours of culture, harvested, and counted

BrdU labeling. BrdU labeling was performed by incubating $\mathrm{K} 562$ cells at $37^{\circ} \mathrm{C}$ in medium containing $100 \mu \mathrm{g} / \mathrm{ml} \mathrm{BrdU}$ (Sigma). After 24 hours, cells were collected, washed with PBS and incubated with Lysis Solution FACs (BD Bioescience). Then, they were fixed with $1 \%$ paraformaldehyde (Panreac) and NP-40 (Sigma) for 30 minutes at $4^{\circ} \mathrm{C}$. Cells were incubated with Dnase I (Sigma) for 30 minutes and stained with BrdU-FITC for 45 minutes, followed by flow cytometry analysis.

Lentiviral vectors. The HIV packaging (pCMVDR8.91) and VSV-G (pMD.G) plasmids have been described elsewhere [43, 44]. The HIV packaging pCMVDR8.91 encodes gag, pol, tat and rev genes. The pMD.G plasmid encodes the Vesicular Stomatitis Virus (VSV) G protein (VSVg). The lentiviral vector plasmid SEWP (HRSIN-CSGW) [25] encodes the emerald green fluorescent protein (eGFP) under the control of the spleen focus forming virus (SFFV) promoter and contains the Woodchuck post-regulatory element (WPRE). The lentiviral vector SPTBNWP was generated by replacing the eGFP cDNA in the SE vector for a $519 \mathrm{bp}$ fragment containing the PTB domain of numb gene with a Myc tag. To do this we generated a PCR fragment from the p-EF-Numb plasmid using the following primers: Forward: 5'CCGGATCCCACCATGGAACAAAAACTTATTTCTGAAGAAGATCTGAACAAACTACGGC AAAGCTTCAGG-3' and Reverse: 5'-CGCGCGGCCGCCTACTACTACTTCTCCCGC TTCTGTTTACGCTC-3' and cloned it into pGEM-T easy vector (Promega Corp.). The 519 bp fragment containing the PTB domain of numb and the myc tag was excised from pGEM-T by BamHI-Notl digestion and inserted into the lentiviral vector backbone. For, vector production, 293T cells were transfected with the three plasmids described above (pCMVDR8.91, pMD.G and SEWP or SPTBNWP) using Lipofectamine 2000 (GibcoBRL) as 
previously described [45]. Two days after transfection, supernatants containing vector particles were harvested and filtered through $0.22 \mathrm{um}$ and frozen at $-80^{\circ} \mathrm{C}$ until use. Lentiviral particles were concentrated by ultrafiltration at $2000 \times \mathrm{g}$ and $4^{\circ} \mathrm{C}$, using $100 \mathrm{kDa}$ centrifugal filter devices (Amicon Ultra-15, Millipore, Billerica, MA)

\section{Acknowledgments}

The work was supported by grants SAF2014-53526 (to JL), BFU2007-67476 and BFU201021634 (to MC) from Spanish Ministry of Economy and Competitiveness (MINECO), and RD12/0036/0033 (to JL), RD12/0036/0054 (to AB) and RD12/0019/0006 and PI12/01097 (to FM) from Instituto Carlos III, and grant PI-57069 from CICE, FEDER/Fondo de Cohesion Europeo (FSE) de Andalucía 2007-2013 (to FM). The funding from MINECO and Instituto Carlos III was co-sponsored by the European Union FEDER program. EGA was supported with a JAE-doc contract form CSIC, MCL-N was supported by the FPU program from MINECO and LG-G. We thank Rosa Blanco for excellent technical advice by the FPI program from MINECO.

\section{REFERENCES}

[1] J.V. Melo, D.J. Barnes, Chronic myeloid leukaemia as a model of disease evolution in human cancer, Nature reviews, 7 (6) (2007) 441-453.

[2] A. Quintas-Cardama, J. Cortes, Molecular biology of bcr-abl1-positive chronic myeloid leukemia, Blood, 113 (8) (2009) 1619-1630.

[3] R. Ren, Mechanisms of BCR-ABL in the pathogenesis of chronic myelogenous leukaemia, Nature reviews, 5 (3) (2005) 172-183.

[4] M. Savona, M. Talpaz, Getting to the stem of chronic myeloid leukaemia, Nature reviews, 8 (5) (2008) 341-350.

[5] E. Kavalerchik, D. Goff, C.H. Jamieson, Chronic myeloid leukemia stem cells, J Clin Oncol, 26 (17) (2008) 2911-2915.

[6] W. Zhong, J.N. Feder, M.M. Jiang, L.Y. Jan, Y.N. Jan, Asymmetric localization of a mammalian numb homolog during mouse cortical neurogenesis, Neuron, 17 (1) (1996) 4353.

[7] M. Guo, L.Y. Jan, Y.N. Jan, Control of daughter cell fates during asymmetric division: interaction of Numb and Notch, Neuron, 17 (1) (1996) 27-41.

[8] E. Santolini, C. Puri, A.E. Salcini, M.C. Gagliani, P.G. Pelicci, C. Tacchetti, P.P. Di Fiore, Numb is an endocytic protein, The Journal of cell biology, 151 (6) (2000) 1345-1352.

[9] K. Sato, T. Watanabe, S. Wang, M. Kakeno, K. Matsuzawa, T. Matsui, K. Yokoi, K. Murase, I. Sugiyama, M. Ozawa, K. Kaibuchi, Numb controls E-cadherin endocytosis through p120 catenin with aPKC, Mol Biol Cell, 22 (17) (2011) 3103-3119.

[10] P.S. Li, Z.Y. Fu, Y.Y. Zhang, J.H. Zhang, C.Q. Xu, Y.T. Ma, B.L. Li, B.L. Song, The clathrin adaptor Numb regulates intestinal cholesterol absorption through dynamic interaction with NPC1L1, Nature medicine, 20 (1) (2014) 80-86.

[11] C.C. Yap, B. Winckler, Adapting for endocytosis: roles for endocytic sorting adaptors in directing neural development, Front Cell Neurosci, 9 (2015) 119. 
[12] M.A. McGill, S.E. Dho, G. Weinmaster, C.J. McGlade, Numb regulates post-endocytic trafficking and degradation of Notch1, The Journal of biological chemistry, 284 (39) (2009) 26427-26438.

[13] A. Gulino, L. Di Marcotullio, I. Screpanti, The multiple functions of Numb, Experimental cell research, 316 (6) (2010) 900-906.

[14] R. Aguado, N. Martin-Blanco, M. Caraballo, M. Canelles, The endocytic adaptor Numb regulates thymus size by modulating pre-TCR signaling during asymmetric division, Blood, 116 (10) (2010) 1705-1714.

[15] S. Pece, M. Serresi, E. Santolini, M. Capra, E. Hulleman, V. Galimberti, S. Zurrida, P. Maisonneuve, G. Viale, P.P. Di Fiore, Loss of negative regulation by Numb over Notch is relevant to human breast carcinogenesis, The Journal of cell biology, 167 (2) (2004) 215221.

[16] S. Pece, S. Confalonieri, R.R. P, P.P. Di Fiore, NUMB-ing down cancer by more than just a NOTCH, Biochimica et biophysica acta, 1815 (1) (2011) 26-43.

[17] J. Sjolund, C. Manetopoulos, M.T. Stockhausen, H. Axelson, The Notch pathway in cancer: differentiation gone awry, Eur J Cancer, 41 (17) (2005) 2620-2629.

[18] J. Hong, Z. Liu, H. Zhu, X. Zhang, Y. Liang, S. Yao, F. Wang, X. Xie, B. Zhang, T. Tan, L. Fu, J. Nie, C. Cheng, The tumor suppressive role of NUMB isoform 1 in esophageal squamous cell carcinoma, Oncotarget, 5 (14) (2014) 5602-5614.

[19] M.G. Kharas, C.J. Lengner, F. Al-Shahrour, L. Bullinger, B. Ball, S. Zaidi, K. Morgan, W. Tam, M. Paktinat, R. Okabe, M. Gozo, W. Einhorn, S.W. Lane, C. Scholl, S. Frohling, M. Fleming, B.L. Ebert, D.G. Gilliland, R. Jaenisch, G.Q. Daley, Musashi-2 regulates normal hematopoiesis and promotes aggressive myeloid leukemia, Nature medicine, 16 (8) (2010) 903-908.

[20] T. Ito, H.Y. Kwon, B. Zimdahl, K.L. Congdon, J. Blum, W.E. Lento, C. Zhao, A. Lagoo, G. Gerrard, L. Foroni, J. Goldman, H. Goh, S.H. Kim, D.W. Kim, C. Chuah, V.G. Oehler, J.P. Radich, C.T. Jordan, T. Reya, Regulation of myeloid leukaemia by the cell-fate determinant Musashi, Nature, 466 (7307) (2010) 765-768.

[21] F. Thol, C. Winschel, A.K. Sonntag, F. Damm, K. Wagner, A. Chaturvedi, G. Gohring, B. Schlegelberger, M. Lubbert, W. Fiedler, H. Kirchner, J. Krauter, A. Ganser, M. Heuser, Prognostic significance of expression levels of stem cell regulators MSI2 and NUMB in acute myeloid leukemia, Annals of hematology, 92 (3) (2013) 315-323.

[22] S.M. Park, R.P. Deering, Y. Lu, P. Tivnan, S. Lianoglou, F. Al-Shahrour, B.L. Ebert, N. Hacohen, C. Leslie, G.Q. Daley, C.J. Lengner, M.G. Kharas, Musashi-2 controls cell fate, lineage bias, and TGF-beta signaling in HSCs, The Journal of experimental medicine, 211 (1) (2014) 71-87.

[23] J.M. Verdi, R. Schmandt, A. Bashirullah, S. Jacob, R. Salvino, C.G. Craig, A.E.

Program, H.D. Lipshitz, C.J. McGlade, Mammalian NUMB is an evolutionarily conserved signaling adapter protein that specifies cell fate, Curr Biol, 6 (9) (1996) 1134-1145.

[24] C.T. Chien, S. Wang, M. Rothenberg, L.Y. Jan, Y.N. Jan, Numb-associated kinase interacts with the phosphotyrosine binding domain of Numb and antagonizes the function of Numb in vivo, Molecular and cellular biology, 18 (1) (1998) 598-607.

[25] C. Demaison, G. Brouns, M.P. Blundell, J.P. Goldman, R.J. Levinsky, M. Grez, C. Kinnon, A.J. Thrasher, A defined window for efficient gene marking of severe combined immunodeficient-repopulating cells using a gibbon ape leukemia virus-pseudotyped retroviral vector, Hum Gene Ther, 11 (1) (2000) 91-100.

[26] M.T. Gomez-Casares, J.P. Vaque, A. Lemes, T. Molero, M.D. Delgado, J. Leon, C-myc expression in cell lines derived from chronic myeloid leukemia, Haematologica, 89 (2) (2004) 241-243.

[27] N. Ferrandiz, J.M. Caraballo, M. Albajar, M.T. Gomez-Casares, C.E. Lopez-Jorge, R. Blanco, M.D. Delgado, J. Leon, p21(Cip1) confers resistance to imatinib in human chronic myeloid leukemia cells, Cancer letters, 292 (1) (2010) 133-139.

[28] A. Lerga, C. Richard, M.D. Delgado, M. Canelles, P. Frade, M.A. Cuadrado, J. Leon, Apoptosis and mitotic arrest are two independent effects of the protein phosphatases 
inhibitor okadaic acid in K562 leukemia cells, Biochem Biophys Res Commun, 260 (1) (1999) 256-264.

[29] A. Benito, A. Lerga, M. Silva, J. Leon, J.L. Fernandez-Luna, Apoptosis of human myeloid leukemia cells induced by an inhibitor of protein phosphatases (okadaic acid) is prevented by Bcl-2 and Bcl-X(L), Leukemia, 11 (7) (1997) 940-944.

[30] M.E. Gorre, C.L. Sawyers, Molecular mechanisms of resistance to STI571 in chronic myeloid leukemia, Current opinion in hematology, 9 (4) (2002) 303-307.

[31] M.T. Gomez-Casares, E. Garcia-Alegria, C.E. Lopez-Jorge, N. Ferrandiz, R. Blanco, S. Alvarez, J.P. Vaque, G. Bretones, J.M. Caraballo, P. Sanchez-Bailon, M.D. Delgado, J. Martin-Perez, J.C. Cigudosa, J. Leon, MYC antagonizes the differentiation induced by imatinib in chronic myeloid leukemia cells through downregulation of p27(KIP1.), Oncogene, 32 (17) (2013) 2239-2246.

[32] K. Henning, T. Schroeder, R. Schwanbeck, N. Rieber, E.H. Bresnick, U. Just, mNotch1 signaling and erythropoietin cooperate in erythroid differentiation of multipotent progenitor cells and upregulate beta-globin, Exp Hematol, 35 (9) (2007) 1321-1332.

[33] A. Robert-Moreno, L. Espinosa, M.J. Sanchez, J.L. de la Pompa, A. Bigas, The notch pathway positively regulates programmed cell death during erythroid differentiation, Leukemia, 21 (7) (2007) 1496-1503.

[34] A. Lerga, P. Crespo, M. Berciano, M.D. Delgado, M. Canelles, C. Cales, C. Richard, E. Ceballos, P. Gutierrez, N. Ajenjo, S. Gutkind, J. Leon, Regulation of c-Myc and Max in megakaryocytic and monocytic-macrophagic differentiation of K562 cells induced by protein kinase C modifiers: c-Myc is down-regulated but does not inhibit differentiation, Cell Growth Differ, 10 (9) (1999) 639-654.

[35] E. Ceballos, M.J. Munoz-Alonso, B. Berwanger, J.C. Acosta, R. Hernandez, M. Krause, O. Hartmann, M. Eilers, J. Leon, Inhibitory effect of c-Myc on p53-induced apoptosis in leukemia cells. Microarray analysis reveals defective induction of p53 target genes and upregulation of chaperone genes, Oncogene, 24 (28) (2005) 4559-4571.

[36] E. Ishiko, I. Matsumura, S. Ezoe, K. Gale, J. Ishiko, Y. Satoh, H. Tanaka, H. Shibayama, M. Mizuki, T. Era, T. Enver, Y. Kanakura, Notch signals inhibit the development of erythroid/megakaryocytic cells by suppressing GATA-1 activity through the induction of HES1, The Journal of biological chemistry, 280 (6) (2005) 4929-4939.

[37] E. Robey, D. Chang, A. Itano, D. Cado, H. Alexander, D. Lans, G. Weinmaster, P. Salmon, An activated form of Notch influences the choice between CD4 and CD8 T cell lineages, Cell, 87 (3) (1996) 483-492.

[38] M.L. Deftos, E. Huang, E.W. Ojala, K.A. Forbush, M.J. Bevan, Notch1 signaling promotes the maturation of CD4 and CD8 SP thymocytes, Immunity, 13 (1) (2000) 73-84. [39] P. La Rosee, M.W. Deininger, Resistance to imatinib: mutations and beyond, Seminars in hematology, 47 (4) (2010) 335-343.

[40] A. Aljedai, A.M. Buckle, P. Hiwarkar, F. Syed, Potential role of Notch signalling in CD34+ chronic myeloid leukaemia cells: cross-talk between Notch and BCR-ABL, PLoS One, 10 (4) (2015) e0123016.

[41] M. Canelles, M.D. Delgado, K.M. Hyland, A. Lerga, C. Richard, C.V. Dang, J. Leon, Max and inhibitory c-Myc mutants induce erythroid differentiation and resistance to apoptosis in human myeloid leukemia cells, Oncogene, 14 (11) (1997) 1315-1327.

[42] M.J. Munoz-Alonso, J.C. Acosta, C. Richard, M.D. Delgado, J. Sedivy, J. Leon, p21Cip1 and p27Kip1 induce distinct cell cycle effects and differentiation programs in myeloid leukemia cells, The Journal of biological chemistry, 280 (18) (2005) 18120-18129.

[43] L. Naldini, U. Blomer, P. Gallay, D. Ory, R. Mulligan, F.H. Gage, I.M. Verma, D. Trono, In vivo gene delivery and stable transduction of nondividing cells by a lentiviral vector, Science (New York, N.Y, 272 (5259) (1996) 263-267.

[44] R. Zufferey, T. Dull, R.J. Mandel, A. Bukovsky, D. Quiroz, L. Naldini, D. Trono, Selfinactivating lentivirus vector for safe and efficient in vivo gene delivery, J Virol, 72 (12) (1998) 9873-9880.

[45] C. Frecha, M.G. Toscano, C. Costa, M.J. Saez-Lara, F.L. Cosset, E. Verhoeyen, F. Martin, Improved lentiviral vectors for Wiskott-Aldrich syndrome gene therapy mimic 
endogenous expression profiles throughout haematopoiesis, Gene Ther, 15 (12) (2008) 930941.

\section{FIGURE LEGENDS}

Figure 1 Construction of KdnNUMB. (A) Schematic drawing of the NUMB protein and the region used as dnNUMB in this study. The Phosphotyrosine-Binding domain (PTB) and Prolin Rich Region (PRR) domains are as described [23]. (B) Schematic drawing of the lentiviral constructs used in this work. LTR, long terminal repeat; $\Psi$, retroviral packaging signal; SFFV, spleen forming focus virus LTR promoter; WPRE, woodchuck hepatitis virus posttranscriptional regulatory element. (C) Immunoblot showing dnNUMB protein expression in K562 transduced with dnNUMB lentivirus, using an anti-Myc tag antibody. Actin levels were determined as a protein loading control of the samples. (D) mRNA levels of the indicated NOTCH target genes, determined by RT-qPCR in KdnNUMB and KGFP cells. The data are mean values from two independent RNA preparations. Error bars are SEM.

Figure 2 Proliferation rate of KdnNUMB Higher proliferation ratio of KdnNUMB vs. control cell line KGFP analyzed by (A) Viable cells counting at different times in culture (mean values of three independent experiments, error bars are SEM); (B) ${ }^{3} \mathrm{H}$-Thymidine incorporation after $72 \mathrm{~h}$ in culture (mean values of two experiments with SEM) and (C) Incorporation of BrdU for 24 hours. (D) dnNUMB overexpression tested by Immunoblot in several dnNUMB-transfected stable clones carrying PCEFL KdnNUMB. (E) BrdU uptake after 24 hours of two different clones, measured by intracellular flow cytometry. K562 cells in the absence of BrdU (thin solid line), control K562 cells (thick solid line) or K562-dnNb cells (broken line). Data are representative of three independent experiments.

Figure 3. KdnNUMB resistance to Imatinib. (A) Viable cell counting along $72 \mathrm{~h}$ of culture after addition of $0.5 \mu \mathrm{M}$ of Imatinib, showing a partial resistance to the antiproliferative effect of the drug. (B) Fraction of cells in S-phase of the cell cycle in KGFP and KdnNUMB treated with $50 \mathrm{nM}$ dasatinib, $50 \mathrm{nM}$ nilotinib or with $0.5 \mu \mathrm{M}$ Imatinib respectively for 24 hours. (C) Reduced imatinib-induced apoptosis assessed by Immunoblot of the cleavage of PARP 24 hours after addition of $0.5 \mu \mathrm{M}$ imatinib. The arrows mark the position of uncleaved (116 kDa) and cleaved PARP (89 kDa). (D) DNA content of KGFP and KdnNUMB cells treated with 1 $\mu \mathrm{M}$ imatinib for $24 \mathrm{~h}$. Cells were stained with propidium iodide and analyzed by flow cytometry. (E) Expression of BCLX and BCL2 analyzed by immunoblot in KGFP cells and $\mathrm{KdnNUMB}$. HeLa and KBcl2 cells were included as controls for the expression of BCLX and $B C L 2$, respectively. Cells were treated for $24 \mathrm{~h}$ with $1 \mu \mathrm{M}$ imatinib. Actin levels were determined as a control for protein loading. The lane " $M$ " contains the molecular weight markers.

Figure 4. Activity of KdnNUMB over BCR ABL and NOTCH pathway. (A) Immunoblot showing higher levels of phospho-BCR-ABL and his phosphorylated substrate P-CRKL in KdnNUMB cells. Actin levels were determined as a protein loading control of the samples. (B) mRNA levels assessed by real time PCR of different NOTCH target genes 48 hours after addition of $0.5 \mu \mathrm{M}$ imatinib.. Mean data of two experiments with SEM bar errors. (C) mRNA expression of indicated erythroid specific genes in KGFP and KdnNUMB cells untreated or 
treated for $24 \mathrm{~h}$ with $1 \mu \mathrm{M}$ imatinib. mRNA was determined by RT-qPCR. Data are relative to the basal expression in KFGP cells. $\beta$-globin mRNA expression is shown in a different scale. (D) Immunoblot showing the expression of $y$-globin protein in KGFP and KdnNUMB cells. Actin levels were determined as a protein loading control. (E) Fraction of hemoglobinproducing cells in KGFP and KdnNUMB cells treated for $36 \mathrm{~h}$ with $0,5 \mu \mathrm{M}$ imatinib. The hemoglobinized cells were scored by the benzidine cytochemical test.

Figure 5. dnNUMB-mediated resistance to imatinib does not depend on Notch signaling. (A) Notch cleavage inhibition by DATP en K562 cells. Cells were treated with 5 $\mu \mathrm{M}$ DAPT and, when indicated, with $1 \mu \mathrm{M}$ imatinib for $24 \mathrm{~h}$. Cell lysates were prepared and the protein levels of cleaved intracellular Notch an alpha-tubulin were assessed by western blot. NICD, NOTCH Intracellular Domain. (B) Cell proliferation of KGFP and KdnNUMB cells treated for $48 \mathrm{~h}$ with $5 \mu \mathrm{M}$ and $10 \mu \mathrm{M}$ DAPT, assessed by cell counting. Data are mean values of two independent experiments, error bars are S.E.M. (C) Cell proliferation of KGFP and KdnNUMB treated with $10 \mu \mathrm{M}$ DAPT and $1 \mu \mathrm{M}$ imatinib as indicated. The cell countings were normalized to the proliferation of untreated cells.

Figure 6. Expression of Notch target genes in KGFP and KdnNUMB. (A) Cells were treated for $24 \mathrm{~h}$ with $1 \mu \mathrm{M}$ imatinib and/or $10 \mu \mathrm{M}$ DAPT as indicated. The mRNA expression of the indicated genes was determined by RT-qPCR and normalized against the expression of $\beta$-actin mRNA. Data are mean values of two independent experiments. (B) Immunoblot showing BCLX levels in KGFP and KdnNUMB treated for $24 \mathrm{~h}$ with $1 \mu \mathrm{M}$ imatinib and $10 \mu \mathrm{M}$ DAPT as indicated. Actin was determined as a protein loading control.

Table 1. List of primer used in the RT-qPCR assays in this work. All primers are form human genes and have a TM of $57^{\circ} \mathrm{C}$

\begin{tabular}{|l|l|l|}
\hline Gene & Forward primer & Reverse primer \\
\hline$\beta$-Actin & AAAATCTGGCACCACACCTTC & TAGCACAGCCTGGATAGCAA \\
\hline BCL2L1/BCLXL & ACATCCCAGCTCCACATCAC & AAGAGTGAGCCCAGCAGAAC \\
\hline CCND1 & CCCTCGGTGTCCTACTTCAA & AGGAAGCGGTCCAGGTAGTT \\
\hline CDK2 & GGAGAACTTCCAAAAGGTGGA & GAGATCTCTCGGATGGCAGT \\
\hline EPOR & CTGGTCGGAGCCTGTGTC & GAGCACGGTCAGCAGCAC \\
\hline$\beta$-globin & TTGCCACACTGAGTGAGCTG & GCCACCACTTTCTGATAGGC \\
\hline Y-globin & GCTCTGAATCATGGGCAGTG & TGAACTGCACTGTGACAAGC \\
\hline HES1 & CGGACATTCTGGAAATGACA & GTGCGCACCTCGGTATTAAC \\
\hline MYC & AAGACTCCAGCGCCTTCTCT & GTTTTCCAACTCCGGGATCT \\
\hline RPS14 & TCACCGCCCTACACATCAAACT & CTGCGAGTGCTGTCAGAGG \\
\hline TCF3 & CCAGACCAAACTGCTCATCC & GGAGCTGAAAGCACCATCTG \\
\hline
\end{tabular}


Figure 1

A

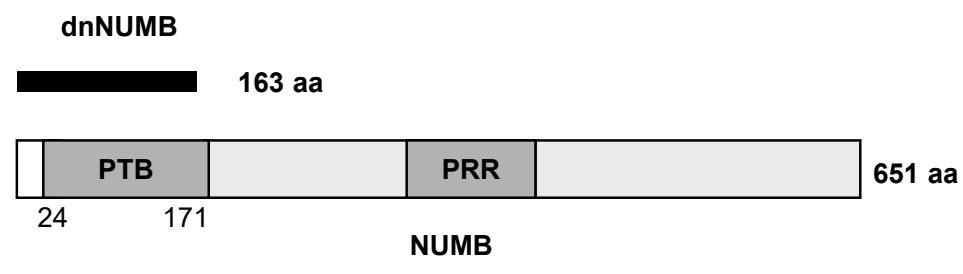

B

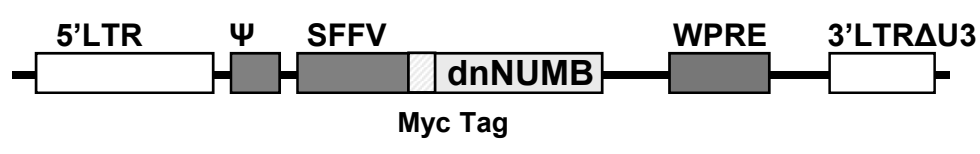

\begin{tabular}{|l|l|l|l|} 
5'LTR & $\Psi$ & SFFV & WPRE \\
\hline & 3'LTRAU3 \\
\hline
\end{tabular}

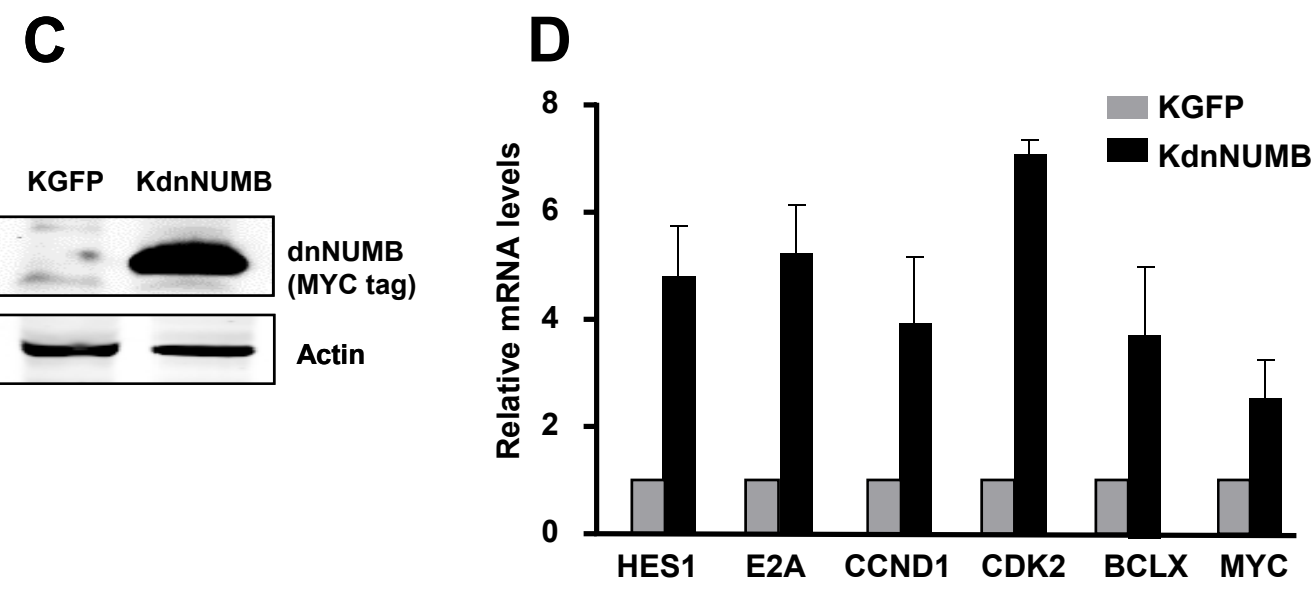


Figure 2

A

B
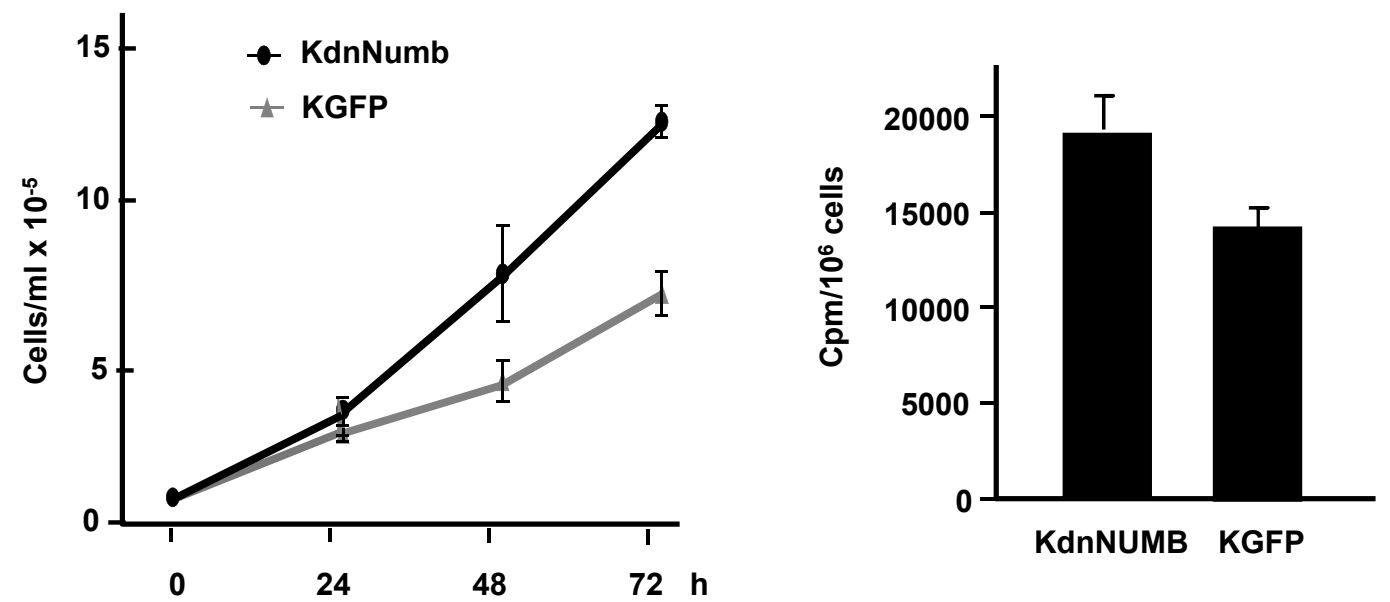

C

D

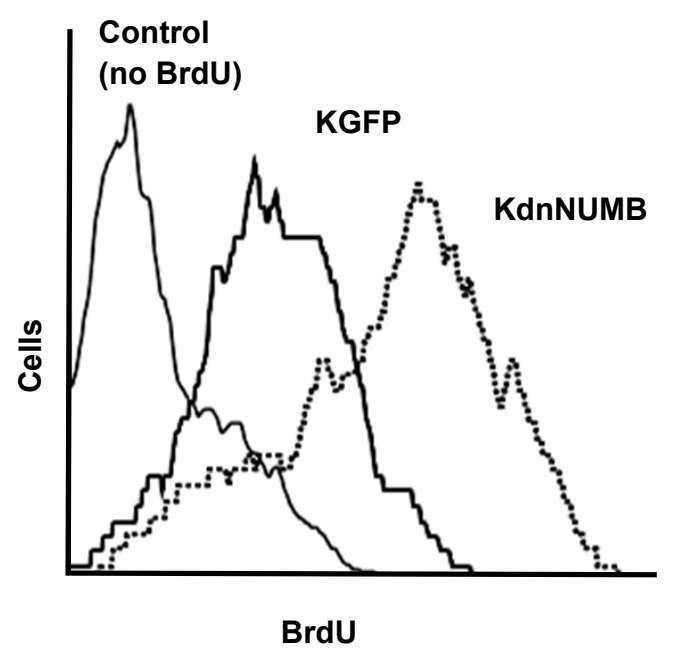

E

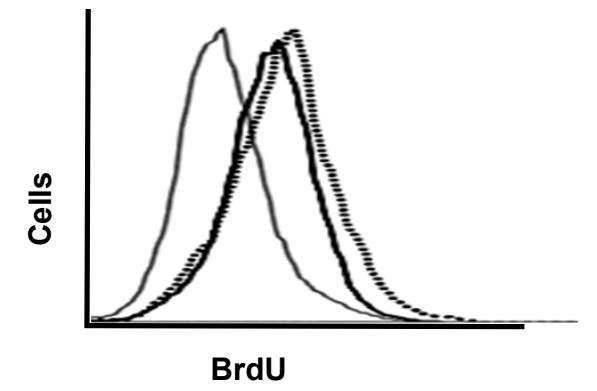




\section{Figure 3}
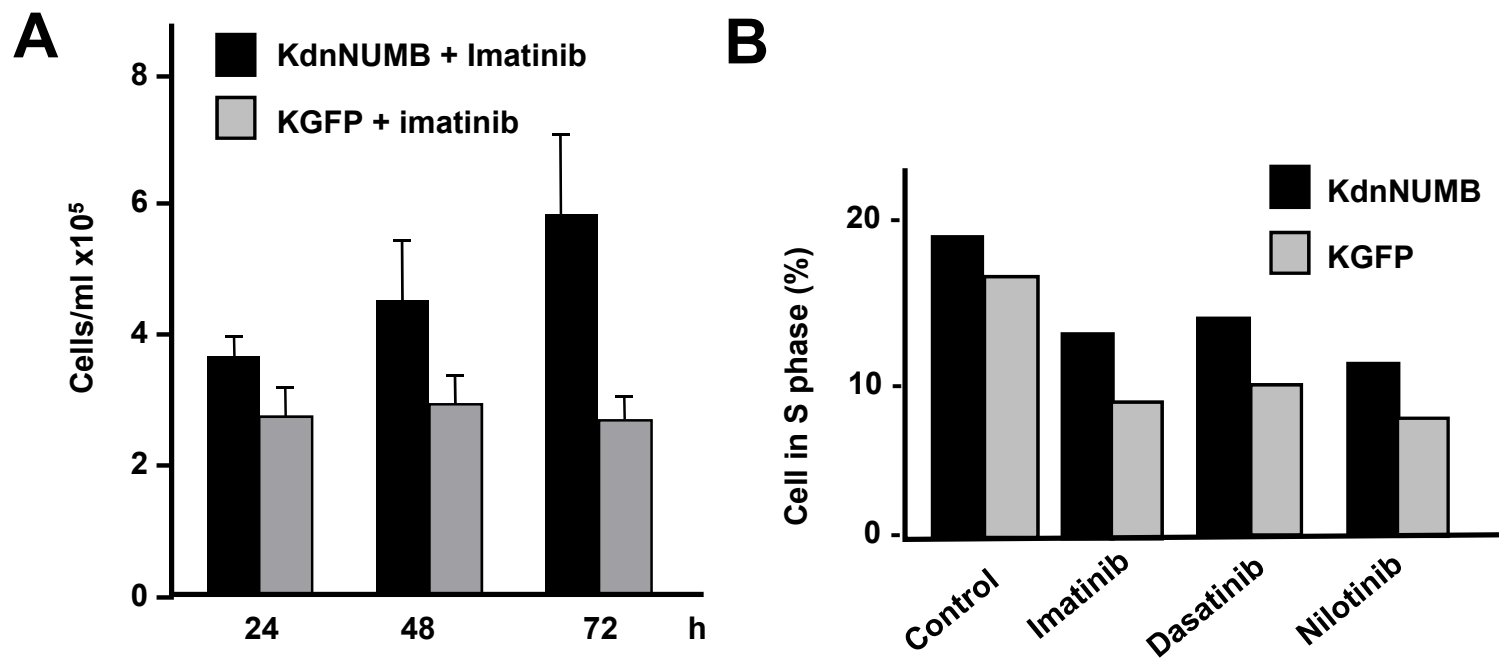

C

D
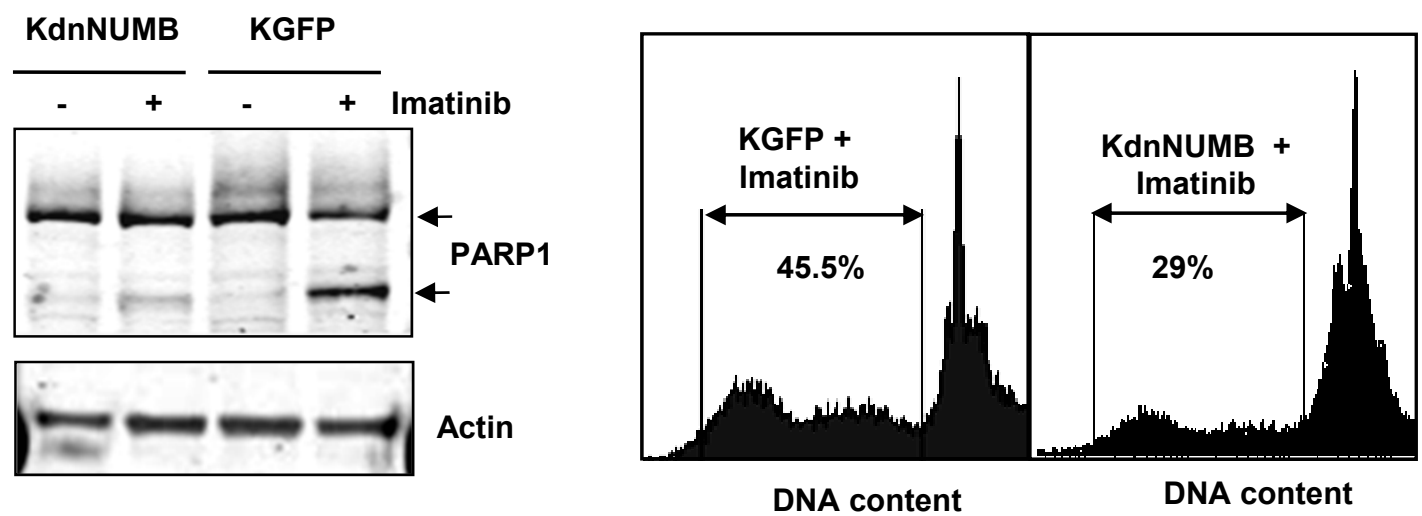

E

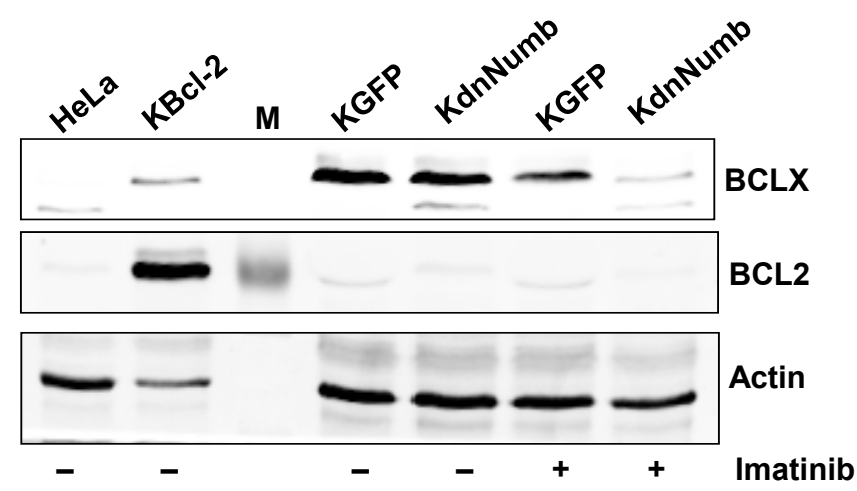




\section{Figure 4}

A

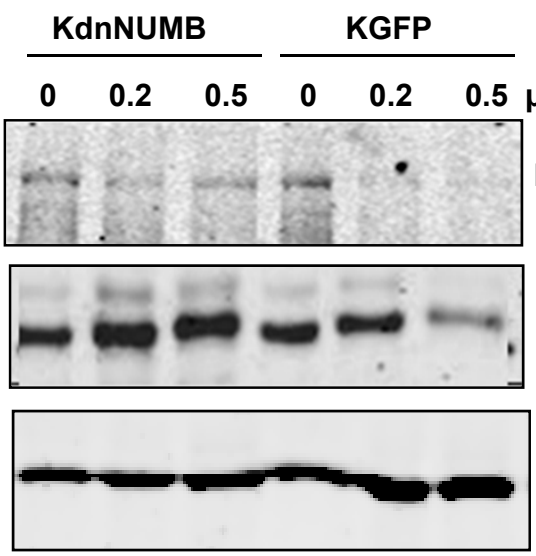

B

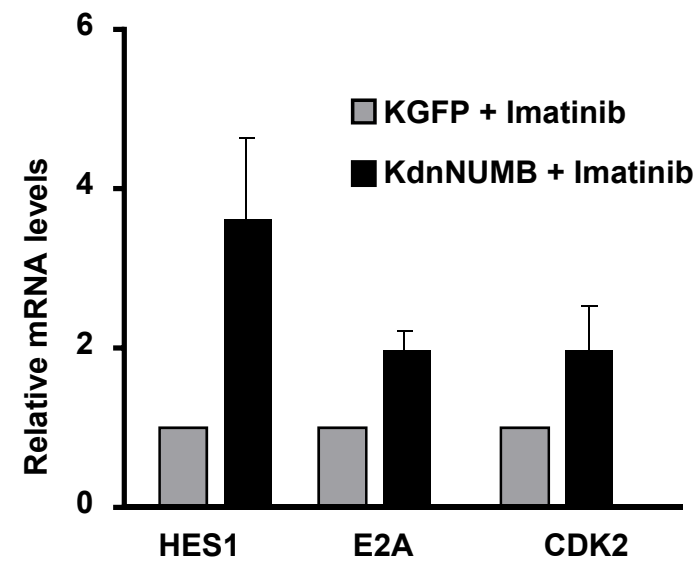

C
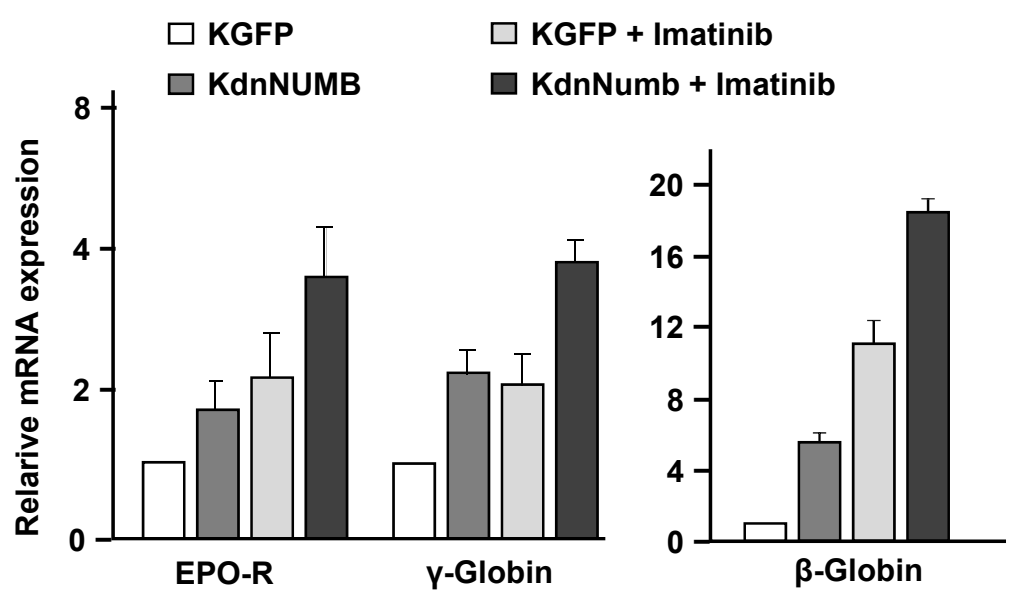

D

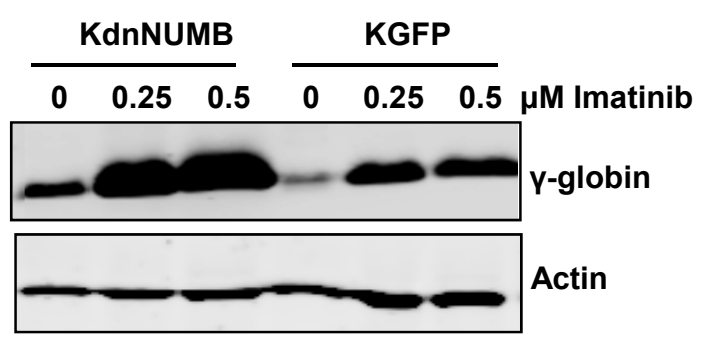

E

KGFP

$\square$ KdnNumb.

$\square$ KGFP + Imatinib

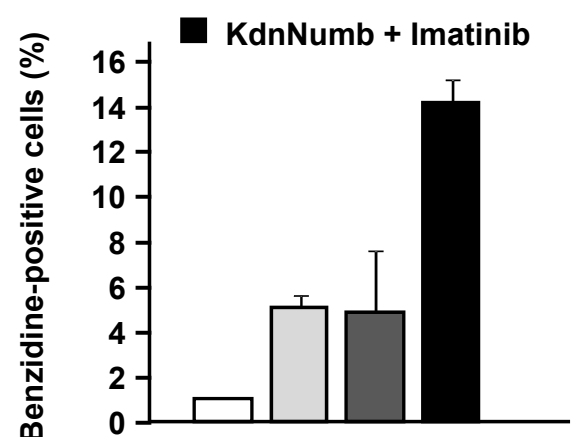




\section{Figure 5}

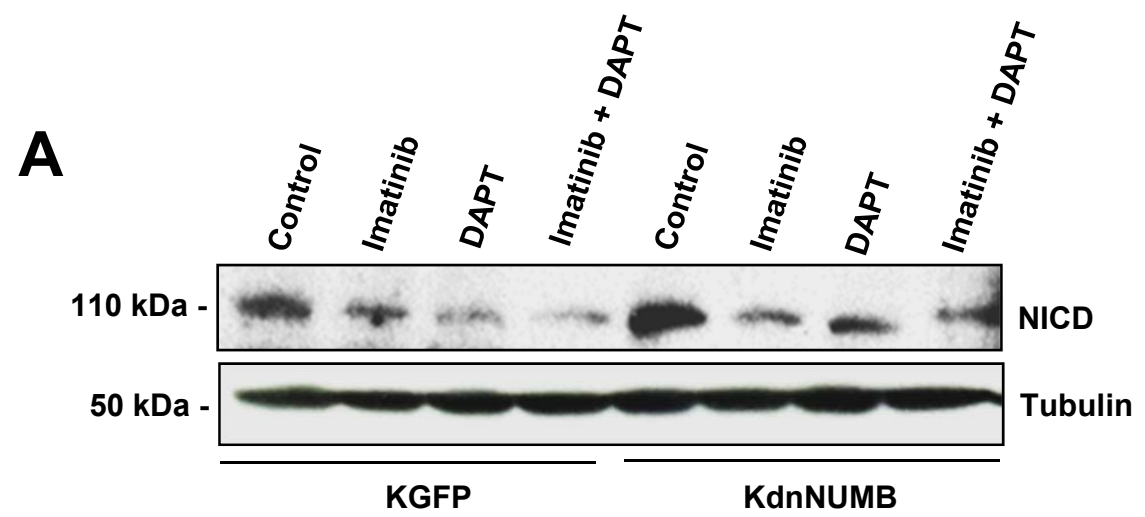

B
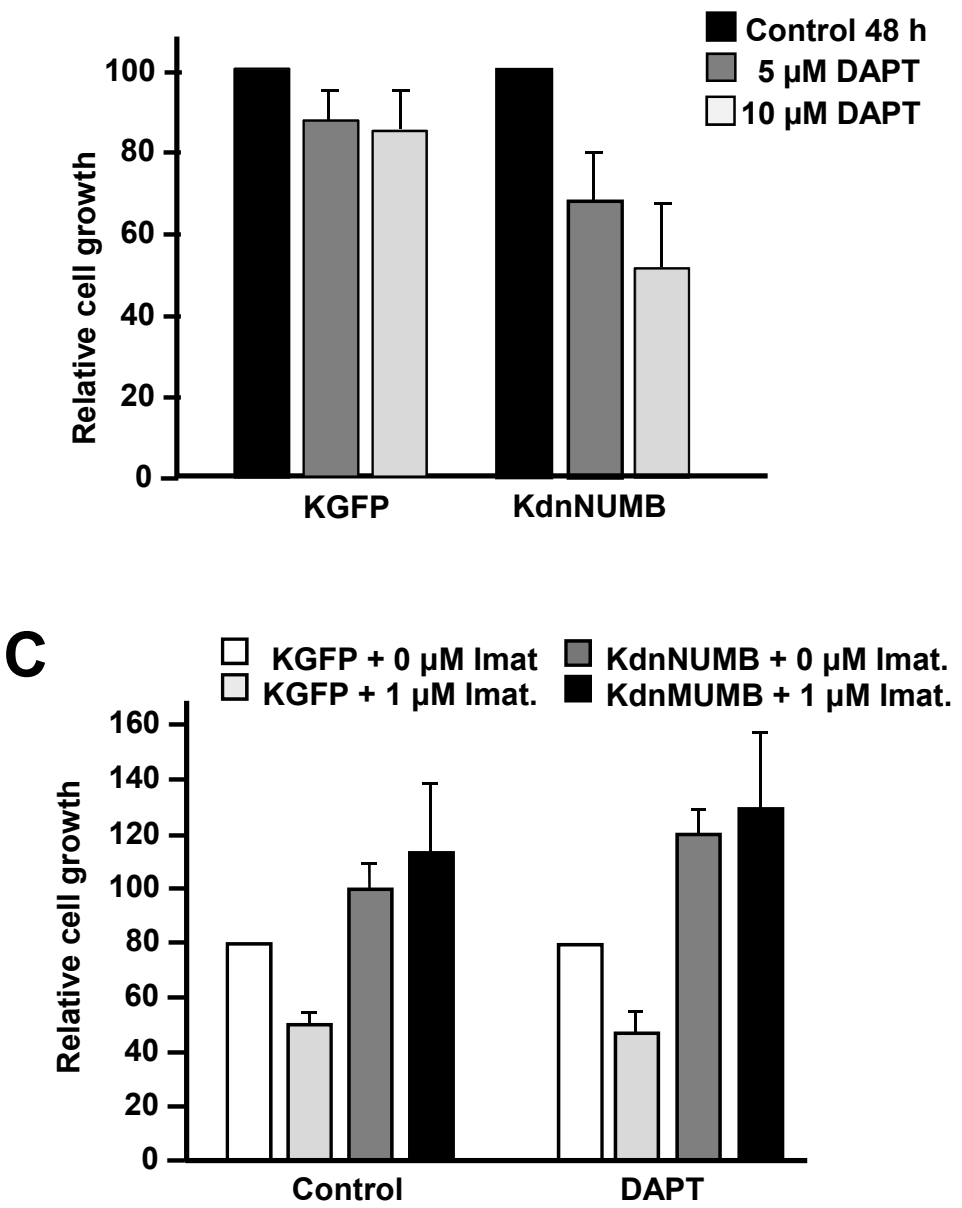


\section{Figure 6}

A
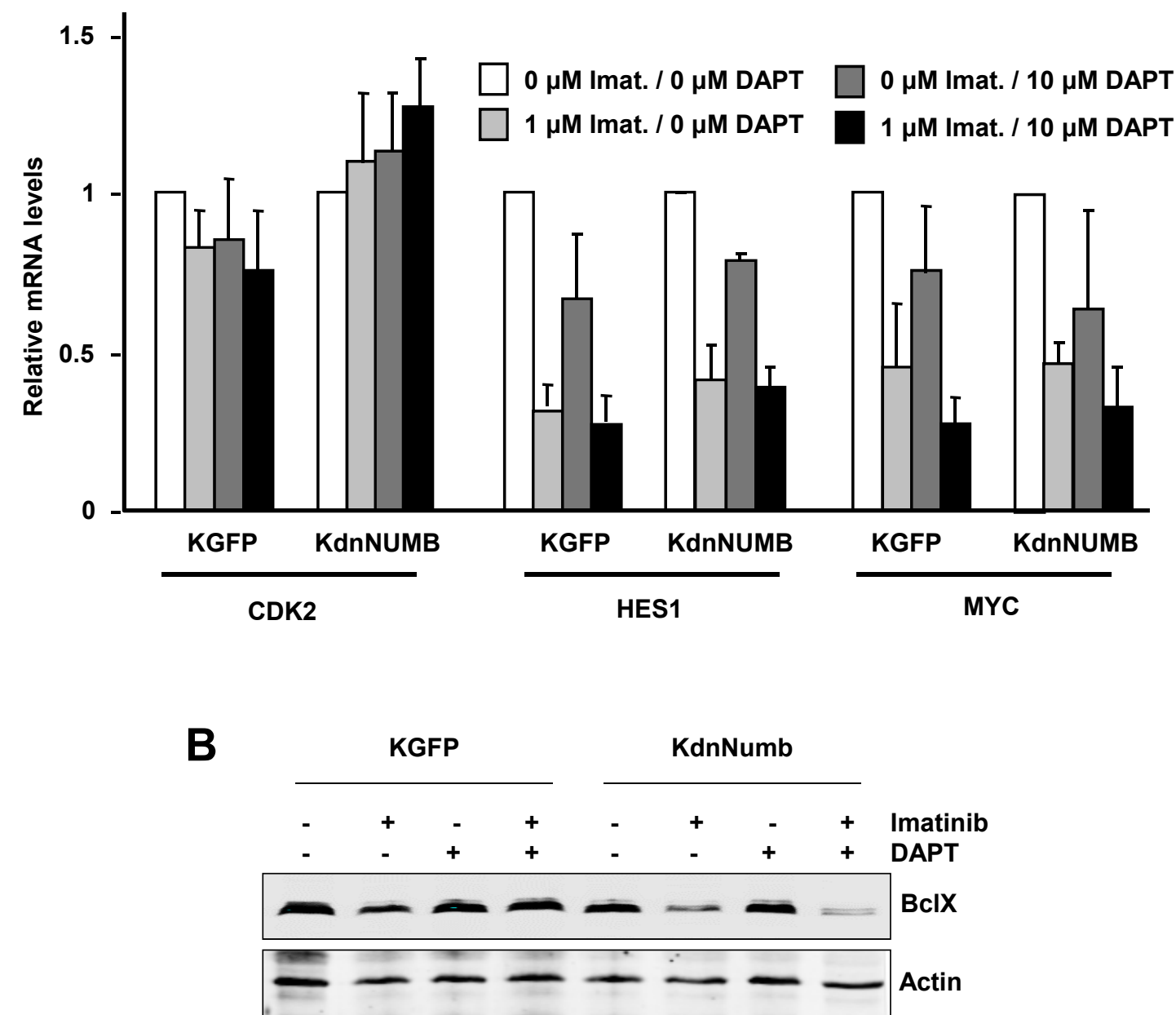